\title{
Analysis of bench testing results and evaluation of economic effect due to introduction of combine harvester cleaning improvement solutions
}

\author{
Evgenia Muratova ${ }^{*}$, Denis Muratov ${ }^{2}$, Elena Kravchenko ${ }^{3}$, Anna Sukhoveeva ${ }^{3}$, and Olga \\ Andreeva $^{3}$ \\ 1Don State Technical University, 1, Gagarin Sq., 344003, Rostov-on-Don, Russia \\ 2Intervesp, 5, Eremenko, Rostov-on-Don, 344041, Russia \\ 3Rostov State University of Economics, 69, Bolshaya Sadovaya, 344002, Rostov-on-Don, Russia
}

\begin{abstract}
One of the possible ways to increase the efficiency of cleaning separation could be the grain fortification of the heap feeding to chaffer sieve and intensification of grain sifting through this sieve. This direction makes it possible to develop the air-sieve cleaning with the pneumatic and inertia separator for high-producing combine harvester. Cleaning improvement will provide agricultural production with the equipment with higher agrotechnical capabilities and lower material expenses.
\end{abstract}

\section{Introduction}

Currently, the issues of reducing the specific indicators of energy consumption, material consumption and fuel costs are particularly relevant in agricultural machinery industry. One of the indirect ways to solve these problems is the increase of agricultural machinery productivity, which can ensure the simultaneous fulfillment of the basic requirements of grain harvesting, reduce the labor intensity and time of harvesting. The operation of combine harvesters shows that their productivity is largely regulated by the acceptable level of cleaning losses (up to $0.5 \%$ ). Despite the ongoing studies, the world practice has not made fundamental changes to the classical air-sieve cleaning design. The cleaning systems basically have the same design with two adjustable lipped screens and adjustable fan. Notwithstanding their significant shortcomings (low specific productivity), these cleaning systems are simple to manufacture and versatile for working with various crops. In this regard, studies related to the intensification of existing working bodies operation and development of the new working bodies functioning satisfactorily with large loads have become crucial because such solutions make it possible to increase the efficiency of combine harvester operation.

\section{Materials and methods}

\footnotetext{
*Corresponding author: geniahab@mail.ru
} 
Preliminary bench studies revealed high cleaning rates of a small grain heap in case of use of new cleaning elements, which provide preliminary fortification of the grain heap before feeding it to the cleaning sieves. The purpose of the bench tests was to verify and confirm the results of previously performed theoretical and experimental research, to define the final design and parameters of air-sieve cleaning with the pneumatic and inertia separator of a small grain heap for combine harvesters.

As a result of previously conducted bench tests [2], data were obtained on the purity of refined grain and grain losses depending on the cleaning load.

According to the obtained sets of samples [2], curves were developed that describe the distribution law of sample data as close as possible. Based on the test data, the functions were constructed showing the dependence of grain losses after cleaning on the specific feed of small heap to cleaning and the dependence of refined grain purity after cleaning on the specific feed of small heap to cleaning.

The main technological parameters of the operation of small grain heap separators of the three tested functional designs [2] are presented in corresponding Figures 1-6. The specific feed of the heap is an important factor affecting the quality of combine harvester air-sieve cleaning.

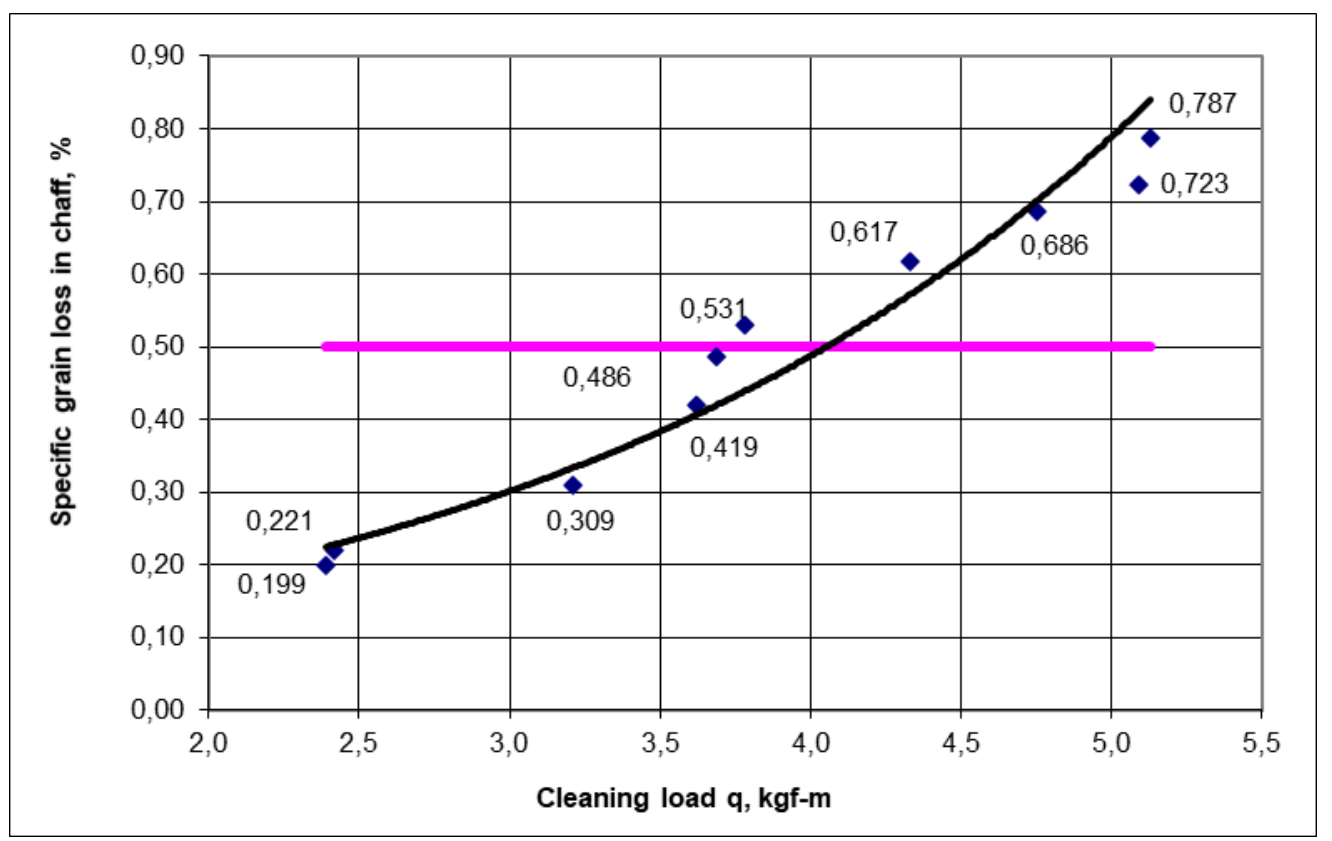

Fig. 1. The dependence of grain losses by series-produced air-sieve cleaning on the specific feed of small heap to cleaning.

The cleaning losses increased and exceeded the permissible $0.5 \%$ at $\mathrm{q}=3.78 \mathrm{kgf}-\mathrm{m}$ in the range of specific feed of heap per 1 meter of sieve width $2.0 \ldots .5 .5 \mathrm{kgf}-\mathrm{m}$. 


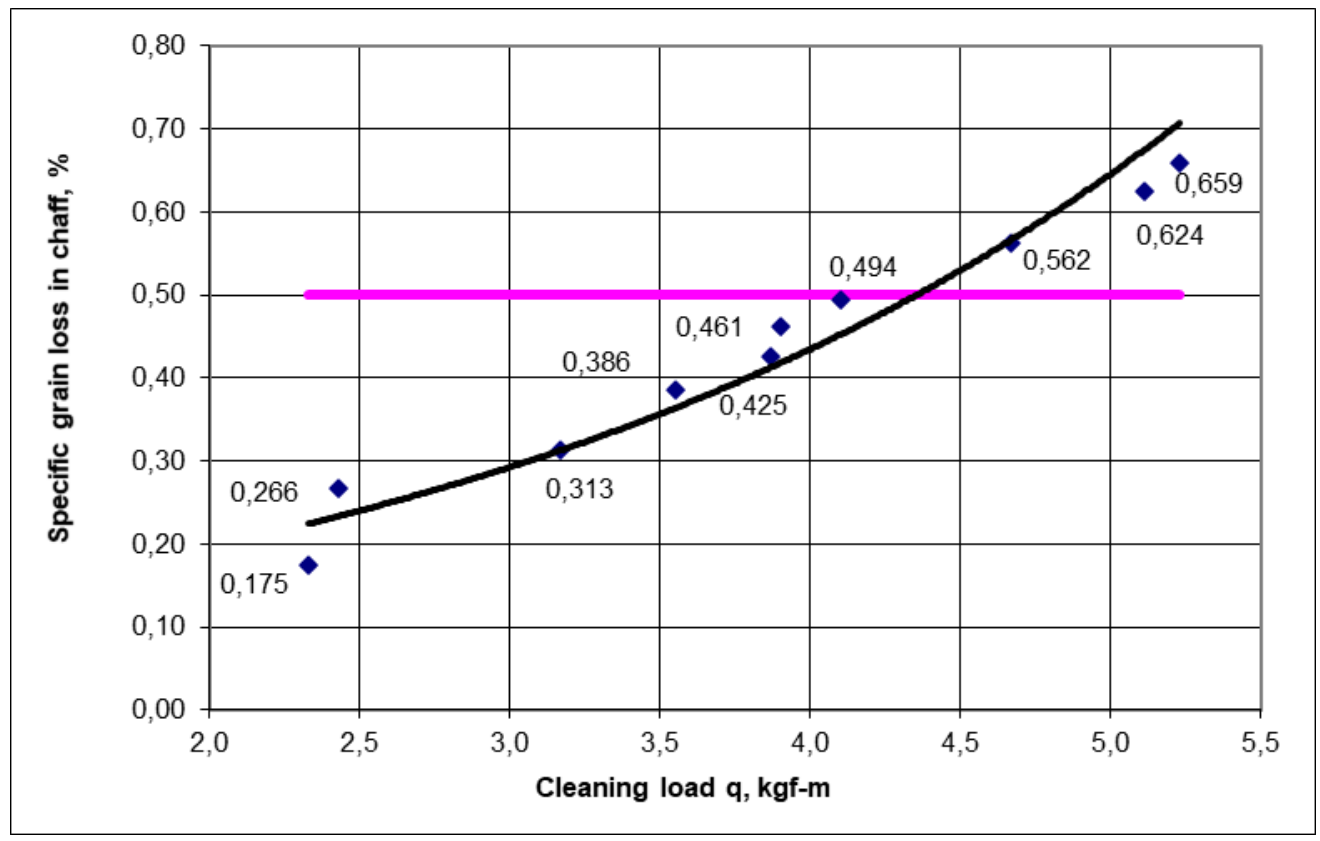

Fig. 2. The dependence of grain losses by the air-sieve cleaning with bladed rotor and series-produced chaffer sieve on the specific feed of small heap to cleaning.

The cleaning losses increased and exceeded the permissible $0.5 \%$ at $\mathrm{q}=4.67 \mathrm{kgf}-\mathrm{m}$ in the range of specific feed of heap per 1 meter of sieve width $2.0 \ldots 5.5 \mathrm{kgf}-\mathrm{m}$.

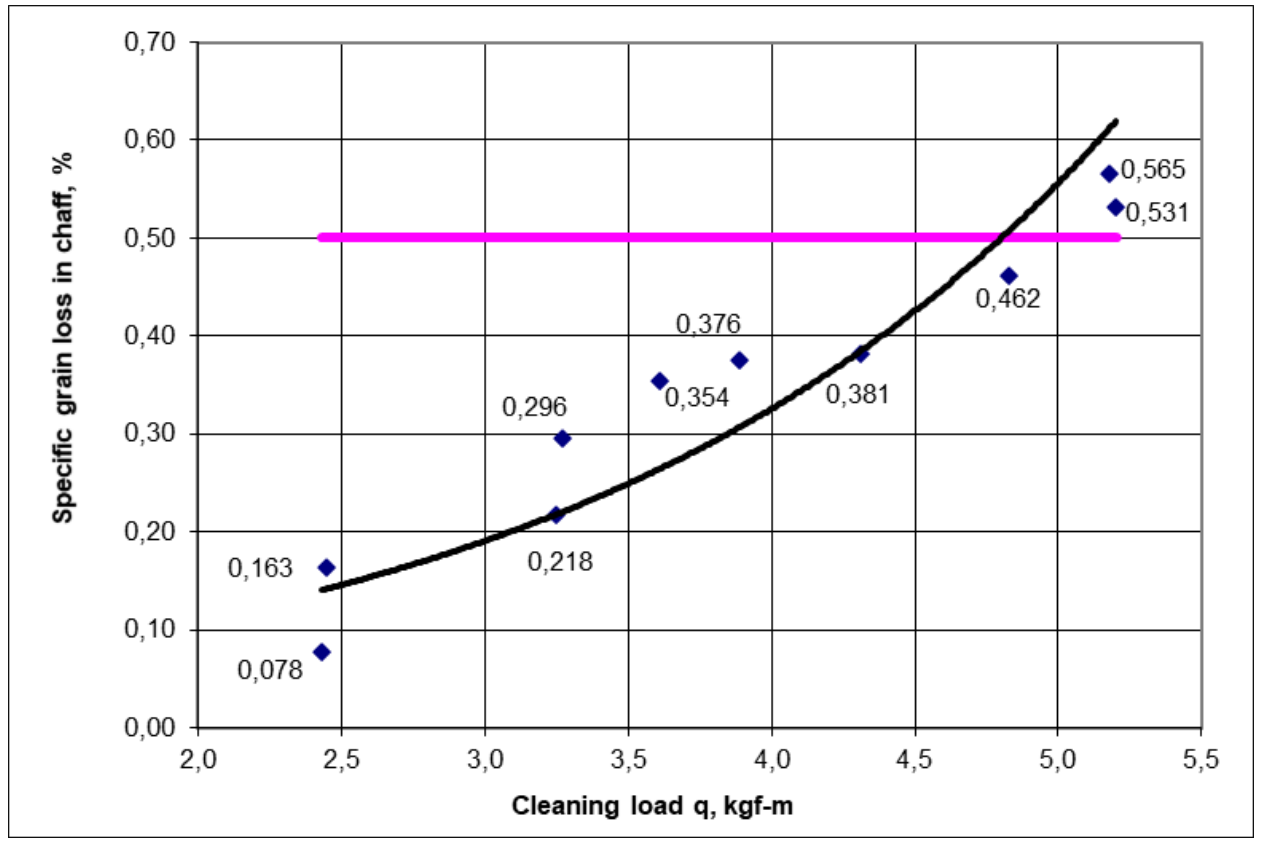

Fig.3. The dependence of grain losses by the air-sieve cleaning with bladed rotor and twosection chaffer sieve on the specific feed of small heap to cleaning. 
The cleaning losses increased and exceeded the permissible $0.5 \%$ atq $=5.20 \mathrm{kgf}-\mathrm{m}$ in the range of specific feed of heap per 1 meter of sieve width $2.0 \ldots 5.5 \mathrm{kgf}-\mathrm{m}$.

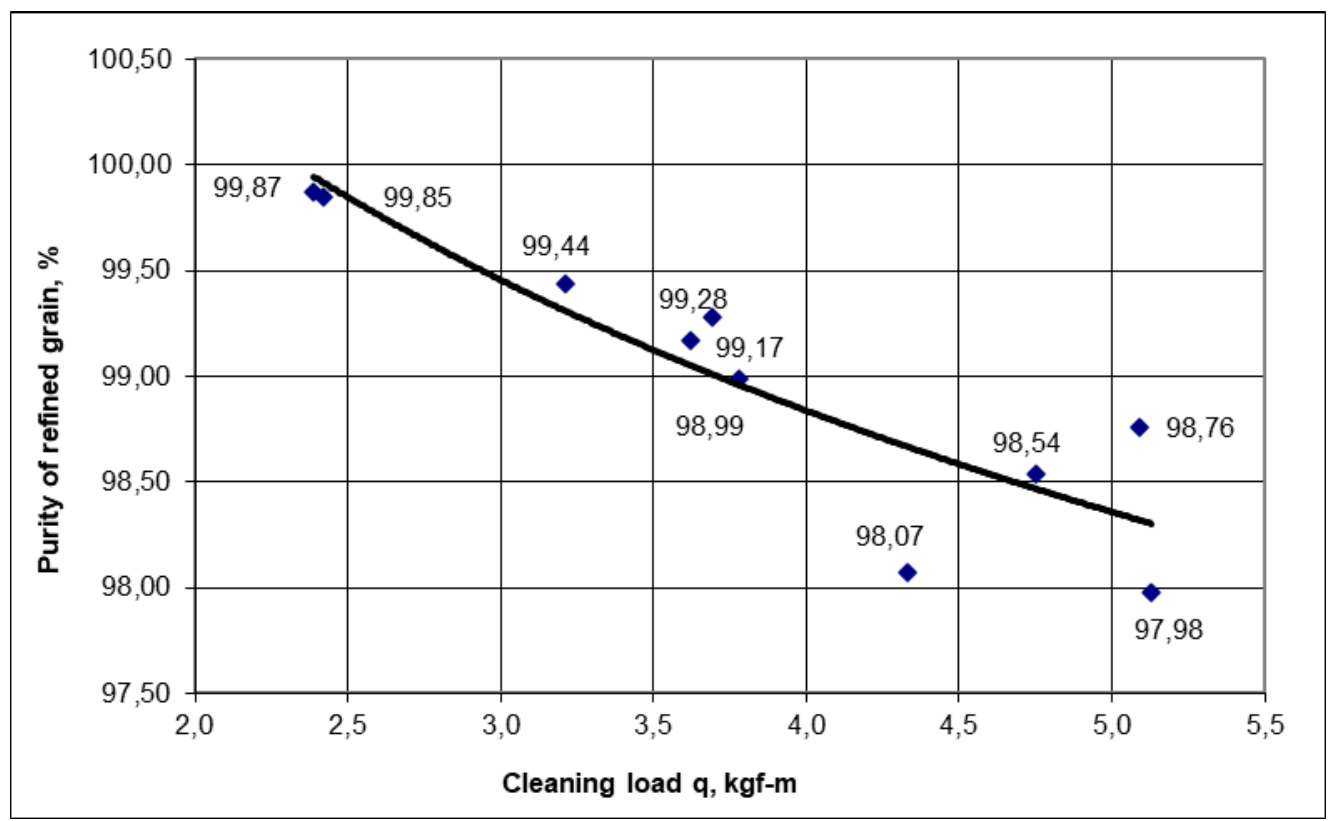

Fig. 4. The dependence of purity of grain refined by series-produced air-sieve cleaning on the specific feed of small heap to cleaning

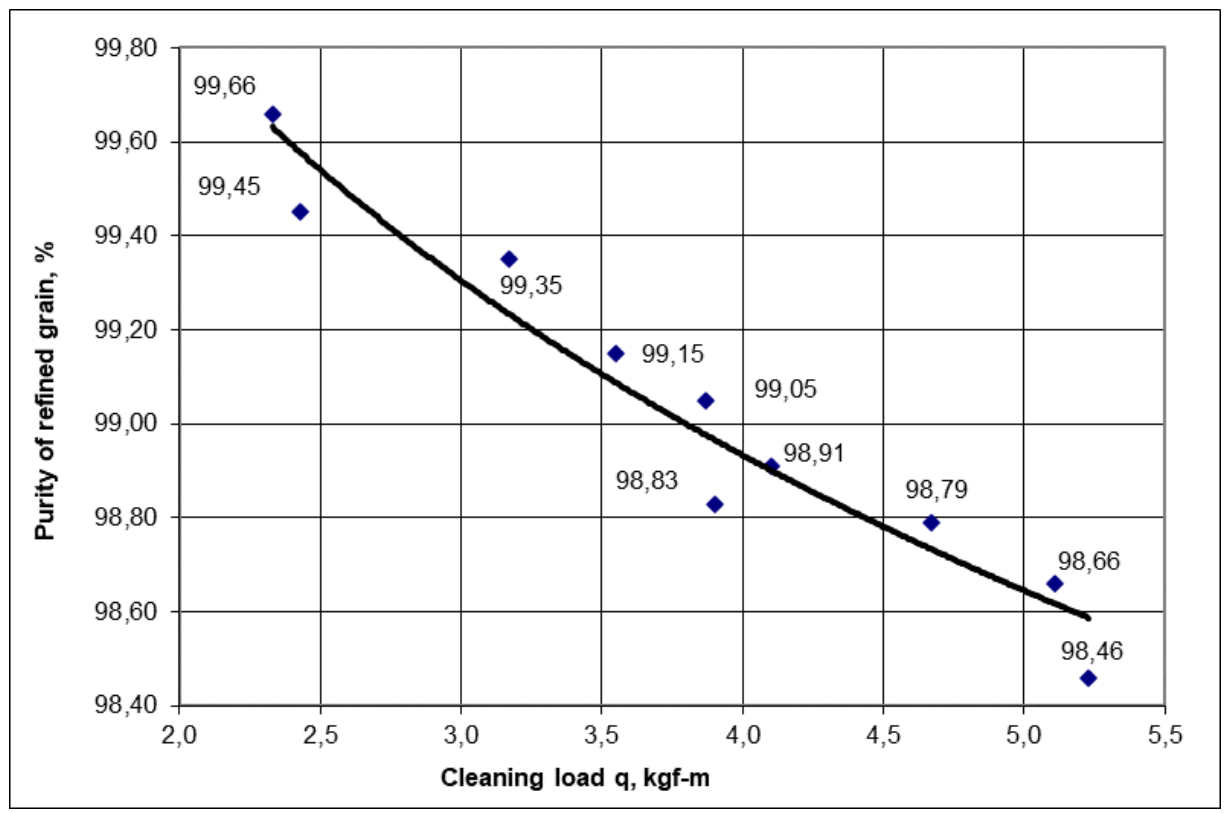

Fig. 5. The dependence of purity of grain refined by the air-sieve cleaning with bladed rotor and series-produced chaffer sieve on the specific feed of small heap to cleaning. 


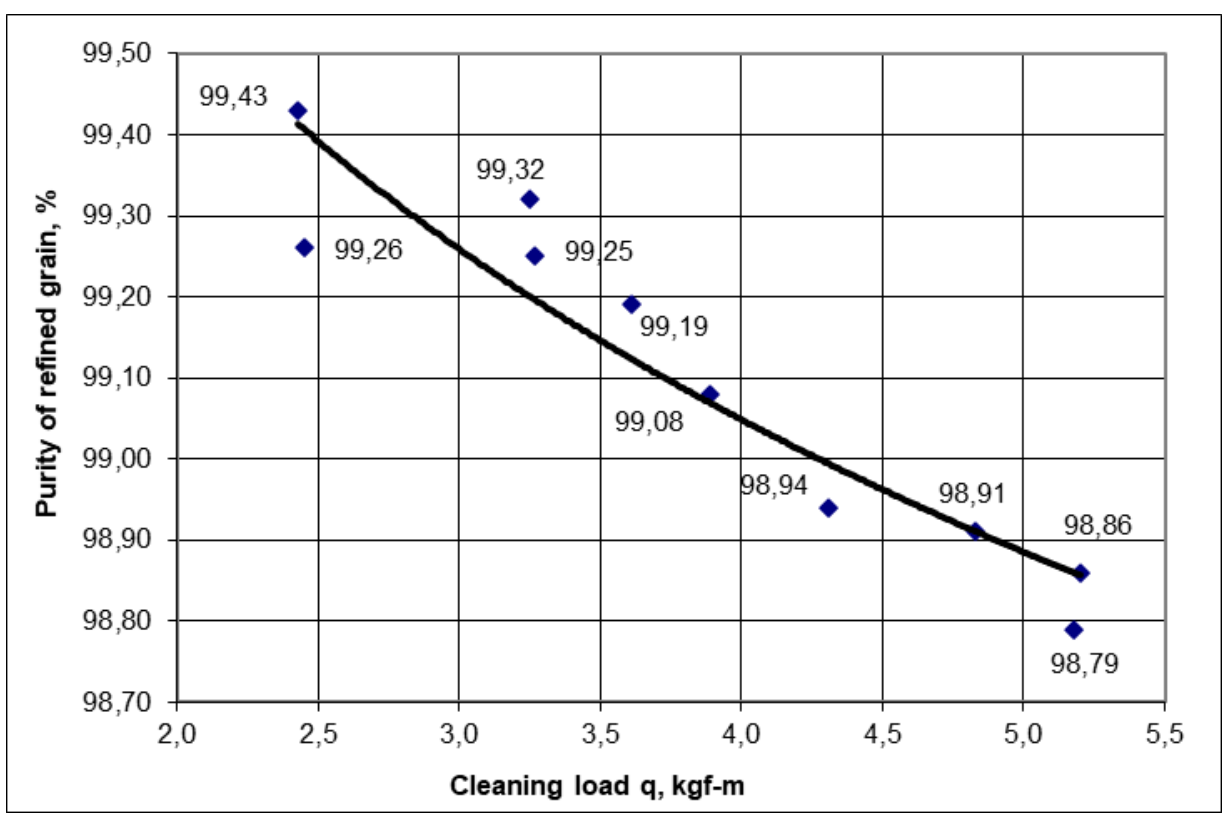

Fig. 6. The dependence of purity of grain refined by the air-sieve cleaning with bladed rotor and two-section chaffer sieve on the specific feed of small heap to cleaning

Calculation of economic efficiency of suggested technical solution is conducted using methodologies described in the source [5].

The following formulas are used to calculate the indicators needed and to define the economic effect.

The volume of season grain losses for combines $P_{z e r}$ is defined as:

$$
P_{z e r}=K_{p} \times F_{z} \times U_{s r}
$$

where $K_{p}$ is harvester's grain loss coefficient;

$F_{z}$ is the area of grain crops of one farm unit, ha;

$U_{s r}$ is the average yield of grain crops, ton / ha.

The volume of additional production for the season $D_{p}$ is calculated using the formula:

$$
D_{p}=P_{z e r}^{b a z}-P_{z e r}^{p r}
$$

The cost of additional production $S_{\text {dop } 1 \text { is defined as: }}$

$$
S_{\text {dop } 1}=D_{p} \times C_{z a k}
$$

where $C_{z a k}$ is the average farm-gate price of grain, rubles / ton.

The cost of additional products obtained by increasing the combine harvester productivity $S_{\text {dop } 2}$ is determined using a formula: 


$$
S_{d o p 2}=\frac{U_{s r} P_{P} C_{z a k}}{100}\left[\begin{array}{c}
\frac{1+n_{2}}{2} \times n_{2} \times\left(W_{d n_{2}}-W_{d n_{1}}\right)+F_{s e z}-W_{d n_{1}} \\
\times \frac{\left(n_{2}+1\right)+n_{1}}{2} \times\left(n_{1}-n_{2}\right)
\end{array}\right],
$$

where $P_{P}$ is the percent of average grain loss, $\%$;

$W_{d n_{1}}$ and $W_{d n_{2}}$ mean the daily output of combine harvester in basic and project cases, ha;

$n_{1}$ and $n_{2}$ mean the number of full work days per season, days;

$F_{s e z}$ is the seasonal harvesting area, ha.

The discount coefficient $K_{d}$ is defined by the formula:

$$
K_{d}=\frac{1}{(1+E)^{t}}
$$

where $t$ is the number of years before the reduction.

The discounted value of additional production $D S_{\text {dop }}$ is definedas:

$$
D S_{\text {dop }}=S_{\text {dop }} \times K_{d}
$$

The annual economic effect $E_{g}$ is calculated as follows:

$$
E_{g}=D S_{d o p}-K
$$

where $K$ is the loan amount including interest.

The mid-year economic effect $E_{s g}$ is determined using the formula:

$$
E_{s g}=\frac{\sum_{i=1}^{n} E_{g}}{n}
$$

where $n$ is the number of years of project implementation.

The discounted payback period $T_{\text {d.ok }}$ can be defined using the formula:

$$
T_{\text {d.ok }}=\frac{K_{p r}}{E_{s g}}
$$

\section{Results}

The dependencies were established and the following equations were derived after approximating the sets of samples.

Exponential dependence of grain losses after cleaning on the specific feed of small heap to cleaning:

- for series-produced air-sieve cleaning:

$$
y=0,071 e^{0,481 x}
$$

- for the air-sieve cleaning with bladed rotor and series-produced chaffer sieve:

$$
y=0,089 e^{0,395 x}
$$


- for the air-sieve cleaning with bladed rotor and two-section chaffer sieve:

$$
y=0,038 e^{0,535 x} \text {. }
$$

Logarithmic dependence of the purity of refined grain after cleaning on the specific feed of small heap to cleaning:

- for series-produced air-sieve cleaning:

$$
y=-2,15 \operatorname{Ln}(x)+101,8
$$

- for the air-sieve cleaning with bladed rotor and series-produced chaffer sieve:

$$
y=-1,29 \operatorname{Ln}(x)+100,7
$$

- for the air-sieve cleaning with bladed rotor and two-section chaffer sieve:

$$
y=-0,73 \operatorname{Ln}(x)+100,0 \text {. }
$$

The adequacy of the constructed regression equations was checked by Fisher's F-test with a confidence factor of 0.95 . All equations are significant and adequate.

Let us calculate the economic efficiency of combine harvester cleaning improvement by equipping it with the suggested pneumatic and inertia separator using the example of one farm (5 harvesters). The key economic indicators are presented in Table 1 comparing two cases for grain harvesting: basic case (without project implementation) and projected case (including project implementation).

Table 1. Calculation of the economic effect due to introduction of suggested solutions for combine harvester cleaning improvement.

\begin{tabular}{|l|c|c|}
\hline Indicator & $\begin{array}{l}\text { Basic case (without project } \\
\text { implementation) }\end{array}$ & $\begin{array}{c}\text { Projected case } \\
\text { (including project } \\
\text { implementation) }\end{array}$ \\
\hline Number of harvesters in the farm, pcs & 5 & 5 \\
\hline $\begin{array}{l}\text { Required investments in the improvement of } \\
\text { harvesters, thousand rubles }\end{array}$ & - & 195 \\
\hline Yield, ton / ha & 24.7 & 4.05 \\
\hline Volume of season grain losses, ton & - & 205.5 \\
\hline $\begin{array}{l}\text { Volume of additional production for the season, } \\
\text { ton }\end{array}$ & - & 37.1 \\
\hline $\begin{array}{l}\text { Cost of additional production obtained by } \\
\text { reducing grain losses and increasing cleaning } \\
\text { productivity, thousand rubles }\end{array}$ & 88329.5 & 520.33 \\
\hline Gross production value, thousand rubles & 68897 & 68849.83 \\
\hline Total production costs, thousand rubles & - & 224.2 \\
\hline $\begin{array}{l}\text { Loan repayment including interest, thousand } \\
\text { rubles }\end{array}$ & 19432.5 & 20211.33 \\
\hline Net profit, thousand rubles & - & 778.83 \\
\hline Net profit growth, thousand rubles & 28.2 & 29.54 \\
\hline Product profitability, \% & 22 & 22.75 \\
\hline Sales profitability, \% & & \\
\hline
\end{tabular}

The indicators of economic efficiency for the suggested project shown in Table 1 make it possible to define the value of additional net profit that can be obtained by the farm because of reducing grain losses and increasing the productivity of combine harvesters due to the implementation of suggested technical solutions for cleaning improvement. The volume of season grain losses may decrease by $15 \%$ in the projected case. The total cost of additional 
production obtained due to the implementation of suggested technical solutions amounts to 520330 rubles. The net profit in the projected case amounts to 778830 rubles or $4 \%$ more than the same indicator in the basic case. As a result, the implementation of the suggested project can have a positive effect on the farm's economic indicators increasing product profitability by $1.34 \%$ and sales profitability by $0.75 \%$.

We will also use the discounting method to determine the annual economic effect and the discounted payback period of the project under discussion, taking into account possible risks and uncertainties. The calculated economic indicators for 5-year period, with other variables unchanged, are provided in Table 2.

Table 2. Calculation of the annual economic effect and discounted payback period for the projected case.

\begin{tabular}{|c|c|c|c|c|c|}
\hline \multirow{2}{*}{ Indicators } & \multicolumn{5}{|c|}{ Years } \\
\hline & 1 year & 2year & 3year & 4year & 5year \\
\hline $\begin{array}{l}\text { Investments in the improvement of harvesters, } \\
\text { thousand rubles }\end{array}$ & 195 & - & - & - & - \\
\hline Loan amount, including interest, thousand rubles & 224.2 & - & - & - & - \\
\hline $\begin{array}{l}\text { Cost of additional production obtained by } \\
\text { reducing grain losses and increasing cleaning } \\
\text { productivity, thousand rubles }\end{array}$ & 520.33 & 520.33 & 520.33 & 520.33 & 520.33 \\
\hline Discount coefficient & 0.8696 & 0.8264 & 0.6575 & 0.5718 & 0.4972 \\
\hline $\begin{array}{l}\text { Discounted cost of additional grain production, } \\
\text { thousand rubles }\end{array}$ & 452.46 & 430.02 & 342.13 & 297.50 & 258.70 \\
\hline Annual economic effect, thousand rubles & 228.26 & 430.02 & 342.13 & 297.50 & 258.70 \\
\hline Mid-year economic effect, thousand rubles & & & 311.32 & & \\
\hline Discounted payback period, years & & & 0.72 & & \\
\hline
\end{tabular}

The calculation is made using the discount rate of $15 \%$. The results presented in Table 2 show that the implementation of suggested technical solutions will provide the annual economic effect and cover financial investments in the first year of the project due to reducing grain losses and increasing the productivity of combine harvesters. The mid-year economic effect of the combine cleaning improvement project amounts to 311320 rubles and discounted payback period amounts to about 9 months. 


\section{Conclusions}

The following conclusions can be made on the basis of obtained results of the bench tests conducted.

- the patterns of changes in grain losses by the investigated air-sieve cleaning and purity of refined grain depending on the feed of grain to the thresher are approximated by nonlinear regression equations, which make it possible to predict the efficiency of the air-sieve cleaning operation;

- when using modern combines for harvesting various crops, a combined chaffer sieve with an increased effective screening area of fin on the remaining length of the sieve and a series-produced shoe sieve can be recommended for two-section air-sieve cleaning, since this design showed minimal grain losses with satisfactory grain purity and is characterized by the adequate versatility.

The calculation of economic effect, carried out on the example of one farm unit, showed a possible increase of farm's net profit by $4 \%$, increase of product and sales profitability with the discounted payback period of the project of about 9 months. According to the feasibility study, it can be concluded that the solution of improvement of small grain heap cleaning, considered in the article, will help to reduce grain losses and increase of cleaning productivity, as a result of which the economic benefit can be obtained.

\section{References}

1. E. Muratova, D. Muratov, E. Makarenko, S. Shepelev, O. Korobeynikova, V. Chegge and Y. Kabanova, E3S Web Conf, 175, 01009 (2020) doi.org/10.1051/e3sconf/202017501009

2. E. Muratova, D. Muratov, E. Kravchenko, A. Sukhoveeva, O. Andreeva, E3S Web Conf, 210, 05010 (2020) doi.org/10.1051/e3sconf/202021005010

3. N.S. Plaskova, N.A. Prodanova, A.S. Samusenko, E.A. Erzinkyan, K.A. Barmuta, R.A. Shichiyakh, International Journal of Engineering and Advanced Technology, 29132916 (2019) DOI: 10.35940/ijeat.A1213.109119

4. A. Butovchenko, A. Doroshenko, A. Kol'Cov, V. Serdyuk, E3S Web Conf, 135, 01081 (2019) doi.org/10.1051/e3sconf/201913501081.

5. V.V. Mazur, K.A. Barmuta, S.S. Demin, E.A. Tikhomirov, M.A. Bykovskiy International Journal of Economics and Financial Issues, 6 (1S), 270-274 (2016)

6. K.A. Barmuta, E.M. Akhmetshin, I.Y. Andryushchenko, G.V. Meshkova, A.O. Zekiy, Entrepreneurship and Sustainability Issues, 8 (1), 945-959 (2020) doi.org/10.9770/jesi.2020.8.1(63)

7. L.V. Borodacheva, A.F. Goloborodov, A.I. Guseva, A.A. Drozdova, M.P. Glyzina, International Journal of Economics and Financial Issues, 6 (1S), 306-311 (2016)

8. F.A. Kipriyanov, P.A. Savinykh, Foundation for Enviromental Protection and Research, J Biosci, 13 (2), 1651-1658 (2019)

9. K.A. Barmuta et. al., Contemporary aspects of innovation economy and management development, Rostov-on-Don: DSTU publishing center, 159 (2020)

10. A. Izmailov, M. Moskovskiy, D. Podlesniy, MATEC Web of Conferences, 224, 05010 (2018) doi.org/10.1051/matecconf/201822405010.

11. I. Khozyaev, V. Ladyanov, L. Enalyeva, M. Balinskaya, V. Zharov, E3S Web Conf., 135, 01103 (2019) doi.org/10.1051/e3sconf/201913501103. 
12. A. Solonenko, L. Medvedeva and Y. Mostovaya, E3SWeb Conf., 175, 13010 (2020) doi.org/10.1051/e3sconf/202017513010

13. Y Lachuga, A Soloviev, A Matrosov, I Panfilov, V Pakhomov, D Rudoy, Conf. Series: Earth and Environmental Science, 403, 012055 (2019) doi:10.1088/17551315/403/1/012055.

14. K. Timoleanov, D. Savenkov, L., Gorgadze MATEC Web of Conferences, 224, 05020 (2018) DOI: $10.1051 /$ matecconf $/ 201822405020$

15. Y. Tsarev, E. Adamcikova, M. Najie, MATEC Web of Conferences, 224, 05019 (2018) DOI: 10.1051/matecconf/201822405019/ 